\title{
The Strategic Framework for Women's Enterprise: BME Women at the Margins
}

\author{
Cynthia Forson - Researcher
}

School of Business and Management, Queen Mary University of London

Mile End Road, London E1 4NS

Tel: +44207882 2698 E-mail: - c.forson@qmul.ac.uk

Website: - www.qmul.ac.uk

Purpose: Historically the policy approach in the United Kingdom towards female enterprise and Black and Minority Ethnic (BME) business has mirrored the inconsistencies in the approach to small business enterprises generally (DTI, 2002). The policy approach between the 1960s and the end of the 1990s centred on various politically motivated dimensions of small business that generally marginalized BME and women-owned businesses. Presently, in the UK, the Small Business Service (SBS) of the government's Department of Trade and Industry has been given the mandate since 1999 to be "the voice of small firms in government, to help small firms deal with the regulatory burdens and develop a world class business support infrastructure" (Vyakarnam and Gatt, 2000) with a strategic aim to encourage "more enterprise in disadvantaged communities and under-represented groups". As part of the effort to provide a more coherent national strategic approach to women's enterprise policy the government launched the Strategic bFramework for Women's Enterprise (SFWE) in 2003, an umbrella document from which all initiatives to support female entrepreneurship acquire their momentum. However, research has shown that BME women and African-Caribbean women in particular may face these challenges in unique ways that may not be reflected in the experiences of mainstream women (Ram, 1998, Ram et al., 2003, Bank of England, 2003, Marlow et al., 2003, Cabinet Office, 2003).

Design/ Methodology/ Approach: As part of policy documentation review for an ongoing doctoral study, this paper examines the SFWE seeking to explore its provisions and how these relate to BME women.

Findings: The paper concludes that the SFWE approaches the issue of BME women's entrepreneurship as a sub-set of female entrepreneurship and therefore assumes that they will benefit from all gender-based policies. The document treats women as a homogenous group and the acknowledgement of the diversity of female entrepreneurs, particularly BME women's experiences, is not reflected in the action priorities relating to business support provision, access to finance, childcare and caring responsibilities and transition from benefits to selfemployment.

I mplications: The paper shows that there is a need for further research into the experiences of BME women in business in order to address any needs that may be different to that of mainstream women and to support this with policy provisions that are relevant to their needs. The recurrent problem is whether to concentrate on making mainstream business support provision and initiatives responsive to the needs of BME women or to define issues and develop independent initiatives that cater for these needs.

Originality/ Value: The main contribution of this paper is its focus on a significant but under researched group of women business owners in the context of an evidence-based policy approach to entrepreneurship support and highlights the need for a more focused approach to their specific needs if the entrepreneurial potential of all women is to be harnessed.

Key Words: female entrepreneurship, policy, BME women 


\section{The Strategic Framework for Women's Enterprise: BME Women at the Margins}

\section{I ntroduction}

Up until May 2003 there was no coherent national strategic approach to the development of women's enterprise in the United Kingdom although for decades researchers and support groups have been calling for a distinctive approach to supporting women business owners due to their different business ownership profiles such as different motivations for entering business ownership, reduced access to resources, particularly finance, and longer incubation periods.

Historically, a piecemeal approach has dominated the policy landscape with regard to small business development as well as female entrepreneurship. However, in recognition of the different experiences and consequently the different needs of women the Strategic Framework for Women's Enterprise (SFWE) was launched in May 2003 by the Department of Trade and Industry as a policy document designed to "provide a collaborative and long term approach to the development of women's enterprise in the UK" (DTI, 2003). In the main, the Framework highlights the untapped enterprise potential of women and underscores the need to encourage more women into selfemployment by emphasising the main issues faced by women entrepreneurs and the obstacles to entering self-employment and develops action priorities intended to address the issues defined.

The SFWE is a result of the UK government's commitment, in principle, to support Small and Medium Enterprises (SMEs) and the entrepreneurial culture in the United Kingdom encompassed in seven core themes. The themes include encouraging a more dynamic start-up market, building the capability for small business growth, improving access to finance for small business, encouraging more enterprise in disadvantaged communities and under-represented groups such as women business owners, improving small business' experience of Government services and finally, developing better regulation and policy (DTI, 2002b) (emphasis author's). In spite of the government's ambitious rhetoric regarding the promotion and encouragement of small business creation and sustenance, there seems to be a focus on policies aimed at a 'homogenous' group of small businesses, such as women's businesses or black and minority ethnic businesses, and these will inevitably benefit one group more than the other because such groups are not homogenous and disadvantage is experienced in multiple ways. For example, in the United Kingdom, Bradshaw et al (2003) suggest that women are more likely to feel poor and be poorer than men and lack two or more socially perceived necessities. Underlying this problem are several factors: taking time out of work to bring up children, the high number of women in part-time work or low paid work and the gap between women and men's pay. This fact is not peculiar to Britain alone and is reflected in many industrialised nations, and experienced to a harsher extent by women in less developed states where state provision of welfare is limited and in some cases, non-existent. However, for some immigrant and BME women in Britain and elsewhere, the situation is compounded (Bradshaw et al., 
2003) as these socio-economic factors are combined with cultural peculiarities, limited 'symbolic' human capital and limited opportunities in the labour market, thereby making them and their families four times more likely to live in poverty (Berthoud, 1998).

The aim of this paper is to look at the SFWE, in the context of the heterogeneity of the female business population in an attempt to evaluate how successful the document is in addressing the needs of the female entrepreneurs in the light of the intersectionality of the experiences of BME women. The paper begins with a discussion of the rationale for state intervention, with particular emphasis on the position of female entrepreneurs. It then proceeds with an analysis of the historical development of policy on small business locating women's small business ownership in that context, culminating in the emergence of the Strategic Framework for Women's Enterprise. The SFWE document is then analysed in terms of its four main action priorities in order to determine whether the priorities are representative of all women, particularly the interests and needs of BME women. Although the paper focuses on the UK as a case study, the issues highlighted in the analysis will resonate with BME women attempting entrepreneurship in most industrialised countries around the world as evidenced by research on BME women entrepreneurs in the USA.

Policy on female enterprise in the UK is not only generated at the national level. Other actors such as the European Union, Regional Development Agencies (RDAs), local authorities, government departments and Enterprise Agencies all have a part to play. At the institutional level, Chambers of Commerce, financial institutions, Enterprise Agencies and other institutions also influences the policy landscape. Indeed the Framework recognises this multiparty nature of policymaking and aims its vision at the diverse institutions that are concerned with business development and social issues. There is evidence to suggest that in countries where the state recognises the needs of minority groups in self-employment and leads in official policy regarding same, minority self-employed have more business support (Phizacklea and Ram, 1995).In many industrial nations, one could argue that the sheer numbers of small firms in the economy provide justification for the attention that policy makers give to the sector. In the United Kingdom, for example, micro and small firms ( 0 - 50 employees) make up about 99 percent of the firms in the economy and account for approximately 43 percent of jobs (SBS, 2001). However, An examination of UK and other countries' policies on business support provision reveals that at present the most common approach to disadvantage faced by minority groups is one that tends to focus on a single facet of inequality, e.g. either gender, ethnicity or some other factor (Wilson et al., 2004). Current models for tackling disadvantage in business support provision apply overarching principles in remedying such disadvantage that do not always take into consideration the unique circumstances of individuals or the social context of their experiences. The approach taken by the SFWE has been shaped, in the main, by the historical development of women's business support policy. 


\section{The development of policy on female entrepreneurship}

Historically the policy approach towards female enterprise at the macro level has mirrored the inconsistencies in the approach to small business enterprises generally (DTI, 2002a). Policy in the 1960s and 1970s converged on large firms (Scase, 2000) making women, who generally own small and medium enterprises, invisible. This perspective was fostered by a belief that economic growth and national competitive advantage could only be achieved by the economics of large-scale production - a policy direction that led to a plethora of mergers and acquisitions (Scase, 2000). The role of small businesses seemed to be of little significance. In the 1980s the then conservative government highlighted the potential of an enterprise culture driven mainly by a social and employment-related agenda. This new approach regarded new business formation as a route out of the high unemployment levels that existed at the time, supported by some research that suggested that new firms and small businesses were key to dealing with unemployment at the macro level (Birch, 1979). Under these circumstances, although women were targeted there was no direct focus on them. The 1990s then centred on highgrowth start-ups the definition of which varied across the country (with a tendency to link high-growth and high-technology and therefore based on aspirations of owner) in which women were excluded (PROWESS, 2003). The end of the 1990s and beginning of the $21^{\text {st }}$ century has seen a focus on productivity, and entrepreneurship is regarded by the government as being one of the key ways of increasing national income through higher productivity (GEM, 2002). Consequently there has been a marked shift from a tactical approach to female entrepreneurship to a more strategic approach concurrently as there has been a shift away from a view of small businesses generally as a short-term solution for unemployment to seeing them as a significant contributor to economic well being. By virtue of their numbers small firms owned by women give enough grounds for government policy to focus on them. In the UK about 25 percent of micro and small firms are owned by women (SBS, 2001). This number increases to 38 percent in the United States (Brush and Hisrich, 1999).

PROWESS (Promoting Women's Enterprise Support), a trade association of organisations and individuals who support women to start and grow businesses in the UK, has hailed the present government stance as one where women have been placed firmly at the centre of the productivity debate with an acknowledgement of the contribution that female business owners make to the overall long-term vigour of the UK economy. Of course the state is not the only entity that devises although the focus of this paper is policy at the state level. At the meso level Deakins et al (2003) have identified and discussed the benefits and drawbacks of the key policy issues in developing enterprise support for women. They identify these issues as the choice between targeted and mainstream support, direct and indirect provision, diversity management and equal opportunities, and also issues related to stereotypical images of women entrepreneurs. Targeted support arguments usually focus on distinct business support offerings for women as a group as opposed to support for 
women as part of mainstream programmes. Related to this, at another level, is an argument about the heterogeneity of the female business population and the problematic nature of the 'one-size-fits-all-women' targeted provision. Further, in their paper Deakins et al also question the equal opportunity and diversity management arguments, which focus on age, gender, disability, race and sexual orientation as distinct forms of disadvantage to the exclusion of class/poverty. They cite a policy commitment in Scotland to tackle poverty through social inclusion as proof that poverty alleviation programmes can be stratified in ways that enable such programmes to address the double disadvantage faced by women who are also poor. This paper takes their argument further and suggests that some women experience these disadvantages in multiple ways. There are business women who are black and poor but policy is not always able to capture these nuances and complexities of disadvantage.

\section{Research on female entrepreneurship}

The SFWE focuses much of its research evidence on perceived barriers and obstacles to women's enterprise identified in the literature on female entrepreneurship; barriers such as lack of appropriate business support, access to finance, the impact of caring and domestic responsibilities, the transition from benefits to self-employment, lack of appropriate role models and low levels of confidence and self-esteem. As such it is important to review some of the research on female entrepreneurship. Much of the literature on female entrepreneurship has come from small-scale qualitative data that seems to revolve around start-up issues and the motivations of women business owners and there are conflicting research results in some areas. Carter et al (2001) suggest that although there has been some improvement in the methodological direction of work on female entrepreneurship there is little methodical improvement of previous work which has resulted in the cumulative knowledge on female entrepreneurship being inadequate in terms of depth and utility.

Some of the literature has also come under criticism by feminist scholars (e.g. Brush, 1990) who argue that even the literature on female entrepreneurship is gendered because it is based on androcentric research methodology. This paper's author argues that not only is the existing research androcentric, it is also ethnocentric in that it centres on the experiences of the majority white population. Academic researchers worldwide are in agreement that work on women's enterprise is also centred on the needs and experiences of White middle class women without consideration for the needs of 'other' women such as ethnic minorities, whether in the USA (Inman, 2000), Sweden (Mason, 2003), Greece or the UK. As a result of some of these inadequacies in the research on female entrepreneurship, Deakins et al (2003) conclude that:

The launch of the Strategic Framework for Women's Enterprise... has taken place without the benefit of knowledge or investigation into the importance of issues and barriers that women face in starting, developing and growing their 
businesses. Rather, assumptions have been made about their importance. (p.3)

One of the issues they raise is the lack of statistics on female entrepreneurs arguing that the SFWE claims that fewer women start and own companies than men and that this claim is tenuous because the scarcity of data on female entrepreneurship obscures the contribution of women involved in partnerships and family businesses. However, there is little disagreement in the literature with the fact that substantially and in terms of nuance and degree women business owners sometimes face different issues in their bid to start up and run their own businesses. These concerns need to be highlighted and researched further in order to take them out of the footnotes and incorporate them into the substantive agenda of enterprise development.

There is well supported evidence from the literature (see Carter et al., 2001) and indeed internationally, however, that women cite family commitments ten times more than men as a reason for becoming self-employed, they are less likely to be driven by financial motives as opposed to a sense of fulfilment, a significant number of women are pushed into self-employment to avoid the 'glass-ceiling' (Cromie and Hayes, 1988) and have challenges relating to raising finance in the UK (Carter and Cannon,1992), the USA (Buttner and Rosen, 1989), New Zealand (Fay and Williams, 1993) and elsewhere and where all things are equal women are less likely to find this form of investment attractive. Other evidence shows that women's businesses are focused in service and retailing sectors, they have less prior work, training and business experience and women find it more difficult to access resources (finance, labour, social capital) and start with about a third of the finance of men's businesses in all sizes and sectors resulting in women's businesses growing more slowly and staying small, but gender has no impact on whether they are successful or not (Carter et al., 2001). Further women business owners are less likely to use ICT in their businesses (Carter et al., 2002).

One of the problems faced by policy makers and researchers in the UK with regard to female entrepreneurship is the lack of disaggregated data on female businesses and even less so on BME female businesses (Dawe and Fielden, 2005). The main sources of information on self-employment and business activity are the Labour Force Survey, VAT registration data, the population census and information from lenders about business bank accounts. The low turnover of the majority of women's businesses excludes them from VAT registration as they fall below the VAT registration threshold. The Labour Force Survey shows that there has been a moderate growth in female selfemployment in the United Kingdom between 1984 and 2002, a modest 5.3 percent over eighteen years but it also shows that in the five years leading up to 2002 female share of self-employment declined slightly but its reporting on BME women in self-employment involves such few numbers that it is difficult to draw any significant conclusions (Cabinet Office, 2003). Nevertheless there is some evidence to show that the patterns of self-employment among BME women in the UK are different from those of their male counterparts. For example, although among men South Asians (Indians and Pakistanis) have the 
highest levels of self-employment followed by White men and then African Caribbean men the pattern among women is that Indian women have the highest participation rates followed by White women and then African Caribbean women. The least levels of participation are to be found among Pakistani and Bangladeshi women. Regional data also shows that the percentage of female self-employed varies greatly with region with the Northern I reland and Merseyside having the least number of self-employed women.

\section{Methodology}

Academic work on inequality and disadvantage and political organisations working for women's rights have emphasised the need to take an intersectional approach when analysing women's work situation. Intersectionality is defined by the United Nations as follows:

An intersectional approach to analysing the disempowerment and marginalisation of women attempts to capture the consequences of the interaction between two or more forms of subordination. It addresses the manner in which racism, patriarchy, class oppression and other discriminatory systems create inequalities that structure the relative positions of women, races, ethnicities, class and the like...Racially subordinated women are often positioned in the space where racism or xenophobia, class and gender meet.

An intersectional perspective disengages with the traditional additive approach to understanding disadvantage and focuses on the fact that the interaction of different forms of oppression in the lives of, in this case, BME women creates a unique and subtle form of disadvantage. Intersectionality in this instance will centre on the concepts of ethnicity, gender and class. This is the conceptual framework that will be employed in the review of the SFWE in order to assess how well its action priorities address the business support needs of BME women.

\section{The Strategic Framework for Women's Enterprise}

The Strategic Framework for Women's Enterprise (SFWE) developed by the then BME and Women's Enterprise Unit of the SBS and PROWESS was designed to act as an umbrella document from which all business support initiatives for women business owners in the UK will acquire their momentum. Its aims are to emphasise the long-term cultural and social changes required to improve women's business ownership in the UK, provide a crossgovernment policy and research context and highlight the need to provide improved mainstream services alongside targeted provision. Other aims are to encourage an inclusive partnership approach at local, regional and national levels, and provide practical advice and guidelines for business support agencies. Although the Framework is being hailed by its contributors and proponents in promotional material as a breakthrough in women's enterprise support, by its own admission the SFWE is not "intended to prescribe how provision for women's enterprise will develop over the next few years" but it is 
merely "intended to reflect the Government's desire for women's enterprise to be taken seriously" (p.12).

One of the reasons why growth in female entrepreneurship in the United States, for example, has escalated is the existence of the National Association of Women Business Owners, a national body that supports and lobbies on behalf of female entrepreneurs as well as monitoring, measuring and evaluating the effectiveness of women's enterprise support in the United States (Carter et al., 2001). Proposals for the UK equivalent of such an organisation are currently being discussed by the government with the view to launching an organisation made up of practitioners, academics, researchers, policy makers and policy implementers to that will play a more or less similar role on behalf of UK female entrepreneurs as the USA equivalent. In the meantime the Framework attempts to bring together the strands of the currently fragmented limited mainly local programmes and draw them into systematic strategic policy guidelines for delivery by institutional level agencies such as Business Link Operators and the Regional Development Agencies who have been charged with the implementation of the vision of the Framework.

The SFWE acknowledges all the substantive issues relating to female entrepreneurship discussed above and highlights action points related to the barriers identified that it considers will aid in supporting female enterprise and realising the overall objective of increasing the number of women who start and grow businesses in the UK. The action priorities as envisioned by the SFWE are four fold; business support provision, access to finance, childcare and caring responsibilities and transition from benefits to self-employment. These are by no means an exhaustive list of issues faced by women entrepreneurs but constitute the policy priorities envisioned by the SFWE.

In terms of business support provision it is the aim of the SFWE to "ensure that business support provision is effective, appropriate and accessible for anyone who wants to either start or grow a business" (SFWE, 2003 p.34) and the target for the SFWE with regard to BME women was that "by 2006 the number of women from ethnic minority communities receiving business support assistance will be proportionate to their representation in the local/regional population" (SFWE, 2003 p.11). This means that business support provision must be designed to provide for all men and all women. However, their heterogeneity demands supply side products that are flexible and that can be tailored to meet the needs of each individual's requirements, thereby reflecting the needs of the clientele within the wider policy framework (Atherton and Lyon, 2001). Effective policy and support initiatives require greater communication between policy proponents and the target population. The SFWE laudably calls for a coherent cross-governmental approach to female entrepreneurship. For example the issues emanating from research on the transition from benefits to self-employment cannot be addressed by support agencies without the participation and support of the Department for Works and Pensions (DWP), neither can childcare concerns be tackled without the Department for Education and Skills (DfES). Further, the SFWE has left the implementation of the framework's agenda to the Small Business Service 
(SBS) in England, which delivers its services to the small business community through its contractual relationship with Business Link Operators and their partners around the country. With regard to Wales and Scotland the devolved authorities have the remit of providing support in the light of the framework's vision. This is to ensure that local needs are met within the SFWE framework but the existing institutional framework is hardly able to cater to the needs of either female business owners or BME business owners (Carter et al., 2002, Ram and Smallbone, 2003) much less BME women who fall into the gap between the two groups. Further, "the desire for 'joined-up' business support requires joined up strategy and operations" and implementation process of such a strategy is key to its success (Vyakarnam and Gatt, 2000) otherwise it may be easy for the central vision to be lost in the desire to cater to local or specific needs. It can be difficult to focus on the fulfilment of local agendas without watering down the central strategy. Also a lack of data on various dimensions of entrepreneurship seems to hinder this approach and there is a need for more research into the whole area, especially that on BME women in particular.

A further concern identified by the SFWE is the issue of women who attempt to make the transition from unemployment to self-employment with its attendant problems associated with giving up state benefits. There are various support initiatives for those who want to make the transition from benefits to selfemployment (see Marlow et al., 2003 for a list of initiatives), but the take-up by women is relatively low, especially of the self-employment options in state sponsored bridging programmes such as New Deal in the UK (Small Business Service, 2002). Marlow et al (2003) have recently argued that the complexity of the whole benefits system - delays, the changes from benefits to in-work tax credits and the realities of a fragmented and uncertain income make the transition from benefits to self-employment a difficult decision to make. The benefits system, like other policy initiatives, is based on aggregate information without sufficient consideration of the diverse populations with their distinct profiles and trajectories, for each of which the initiative may not be appropriate. Rake (2001, cited in Marlow et al., 2003) also suggests that the benefit system may be gender biased. Marlow et al contend that the architects of the benefit system designed it based on the assumption that a typical benefits recipient would be a male previously employed full time (and with qualifications and sufficient experience to find another job), on benefits for a short time and then back to full time work when a new job is found. Such a view, they argue, is at odds with the female experience of fragmented work patterns, shorter periods in low paid work as well as the higher likelihood of being poor, carrying the majority of the domestic work load, caring responsibilities (for children and aged parents) and sole parenting. The SFWE approaches this issue as a marketing problem rather than a problem with the content and dynamics of the initiatives themselves.

Childcare is an issue for many women who seek to explore work opportunities outside the home irrespective of their background and its importance is highlighted by the SFWE. Indeed the SFWE engages with the fact that the impact of caring and domestic responsibilities has a burdening influence on 
some women's aspirations to start or manage their businesses. As such one of its stated action points is As stated earlier more women than men ( $21 \%$ to $2 \%$ ), regardless of ethnic background, cite family and domestic responsibilities as their motivation for becoming self-employed (Labour Force Survey, Spring 2000).

\section{Business support}

Ram's (1998) study of BME business support revealed some of the difficulties experienced by BME business owners with regard to appropriate and adequate business support. He found that delivery of services was likely to be reactive and due to a lack of data and stereotyping, inappropriate. Further, support agencies were more concerned about meeting the targets of their fund holders rather than addressing their clients' complex needs. A more recent study by Ram and Smallbone (2003) indicates that although there is now a growing awareness of the need to incorporate BME business interests into business support provision only a third of the mainstream business support providers either had a specific policy towards or was involved in specific initiatives targeted at BME businesses. There is a likelihood that given their marginalisation in both support targeted at women and that targeted at ethnic minorities, BME women's considerations will become insignificant in the grand scheme of things.

BME women are disproportionately represented in home working (Felstead et al., 2000) making up about half of the home working force (CRE, 2005) although admittedly many home workers cannot be classified as self-employed due to issues relating to a lack of control over their work. Nevertheless research by the Commission for Racial Equality (CRE, 2005) indicates that reasons BME women give for working from home include "shortage of money, flexible working hours, language barriers, lack of experience and lack of confidence and cultural and family pressure to stay at home, as well as childcare and domestic responsibilities" (emphasis author's). With reference to language barriers and cultural and family pressures to stay at home it could be argued that these are challenges that are faced particularly by BME women. They are also challenges that warrant targeted business support mechanisms for their particular circumstances. Such women are not likely to benefit from mainstream support initiatives that may require them to proactively seek out business support for their ventures and Dawe and Fielden (2005) conclude that Asian women have little or no business support outside their friends and family. Indeed a regular research finding on BME and women's businesses is their reluctance to use mainstream business support agencies. Further such women are also less likely to benefit from the taken-for-granted family support (moral, business or financial) that characterise BME businesses (Anthias and Mehta, 2003) due to the "cultural and family pressure to stay at home" and the gendered nature of such support (Dhaliwal, 2000). In addition to their specific business support needs BME women also suffer from the inadequacies and drawbacks of general BME business support (see discussion above).

Again with regard to access to finance, there is a recognition that it is a particular issue for women but the action priorities do not engage with the fact 
that research has indicated that among women, there is a continuum of experiences in this regard. For example, in a recent study (Ram et al., 2003), compared with white-owned firms, Chinese-owned businesses had a higher propensity to access start-up finance from banks, while African-Caribbean businesses had a significantly lower propensity and South Asian-owned firms had a comparable propensity to white-owned firms. These observations could not be explained on sectoral grounds alone although types of business activities did make a contribution. There were also higher levels of allegations of racism and evidence of mistrust of banks among the African-Caribbean businesses. However, the study also noted that male-owned African-Caribbean businesses seemed to be less successful than female-owned African-Caribbean businesses in this respect. In the words of the study:
...The findings paint a stark picture of the extent of
African/Caribbean disadvantage with respect to finance. In terms of start-up finance, they have less success in accessing bank loans than either their white or other minority counterparts; a higher propensity to turn to non-bank formal sources of start-up finance (including various sources of last resort lending); and a below average propensity to access informal sources of start-up capital... (p.309)

A significant issue in the access to finance that distinguishes African-Caribbean businesses from other ethnic minorities is the failure to use informal sources of start up capital, which the SFWE does not address. Informal sources of start up capital have been identified by the study as being a significant source of capital used by BME businesses (about 50 percent). Even that is unavailable to African Caribbean businesses. According to the study, this is true in spite of the fact that they have a higher propensity to engage in training and use support where provided. Yet the SFWE action points and objectives emphasise heavily on the marketing and training aspects of finance issues. Many of the outputs reflect this emphasis which is based on the premise that all women have access to informal sources of finance, for example, and it is their lack of awareness about other formal and alternatives sources of finance (CDFIs, business angels and banks) that creates the barriers they experience. This assumption of access to informal sources of start-up capital belies findings that BME women sometimes find that due to the patriarchal and gendered nature of domestic relationships they do not have the support of family (particularly male members) when they seek work and careers outside the home (Anthias and Mehta, 2003, Omar et al., 2004) and for some African-Caribbean women this informal [financial] support might not be available due to more egalitarian family structures (Omar et al., 2004).

In the light of the Ram et al study cited above, the Bank of England has called on banks to track the ethnicity of their SME customers and to be more transparent about the evaluation processes used in decision-making on financing of small firms (Bank of England, 2003). The SFWE, of course, also calls for monitoring of the gender of banks' SME customers. A strategic synthesis of these two monitoring processes and further research into the 
specific needs of BME women would contribute to the assessment of the experiences these women in their bid to access finance for their businesses.

Another issue that impinges on BME women's ability to access financial capital for their businesses is the fact that, although all women are more susceptible to segregation and discrimination in the labour market compared to men, generally BME women have higher rates of unemployment in the labour market than white women as a result of a combination of factors (human capital levels, location, housing tenure patterns, geographical clustering, poor health and lack of suitable childcare) (Cabinet Office, 2003). Further, when they engage in work, they tend to engage in work that is lower paid than white women. This is true even of African-Caribbean women who are three times more likely to work than Pakstani and Bangladeshi women and also more likely than white women to work full time. As such they are less likely than white women to have the requisite collateral to raise money with financial institutions and/or savings to start their businesses without going to banks or other institutions.

\section{From benefits to self-employment}

Secondly, the benefits system may also be race biased, compounding its negative effects in the lives of BME women. In a Welfare to Work briefing by the Training and Employment Network (TEN) (2002) the problem was stated as follows:

Given that all New Deal for Lone Parents participants have already suffered from the disadvantage of low income and lone parenthood, then the job outcomes for minority ethnic groups...are markedly worse than the overall picture.

A study in Birmingham using data from January 1998 by Lucinda Platt and Michael Nobel (1999) shows a marked diversity in the experiences of those on low income according to their ethnic group. They define low-income as being in receipt of means tested Housing Benefit and/or Council Tax Benefit. Bangladeshi, Black-Caribbean and Pakistani ethnic groups are over represented in the low-income population and the white population is slightly under represented compared with their respective populations in the Census. They also found that lone parents make up a larger proportion of the BlackCaribbean families than of any other group although the Black-Caribbean lone parents are significantly more likely to be working than those from any other ethnic group and more likely to be women. There is therefore a possibility, which requires further research, that BME women business owners or nascent entrepreneurs may have different needs that need to be addressed by the SFWE specifically rather than being lumped together singularly under genderbased schemes. 


\section{Childcare and caring responsibilities}

Recent research has established that there is increasing policy recognition of the importance of the childcare as a barrier for self-employed women in the United Kingdom and indeed the cause of business failure among women entrepreneurs (Rouse and Kitching, 2005). However, research by the SBS (2004) to determine whether the availability of childcare was a key driver affecting the section of the population considering self-employment /starting up in business as a career option found no direct link between childcare and enterprise. It concluded that although there is evidence to suggest that improved child care leads to increased economic activity among women, factors other than childcare, such as personal choice, previous employment and education level seem to govern carers' options with regard to employment or self-employment. The investigation also concluded that although there may still be a case for improved childcare support it would be more beneficial to women from lower socio-economic groups and some BME women. Such women, the research, suggests, would gain in terms of the move off benefits into paid work and that business ownership or self-employment may then give these women a different option other than low paid low quality part time work.

Research by the Women and Equality Unit (WEU) (Hall et al., 2004) found that BME women have specific needs with regard to childcare that are different to that of white women. For example some of the women in their sample, particularly South Asian women were reluctant to use whatever childcare was available and accessible because they did not cater to the needs of their children. For these women services that offered teachings about cultural beliefs, languages, and also the provision of Halal food were important and such service provision was few and far between making these women rely on either family help or opting to stay at home and look after their own children.

Further many women who find themselves caught between the pressures of finding adequate childcare and working outside the home rely on family members to help out with childcare responsibilities. For some women, particularly African-Caribbean women, lone parenthood combined with family structures that are more egalitarian make a reliance on family members for childcare a challenge. The assumption also, that certain minority women have automatic family from of older female relatives has been challenged by Rana et al (1998) who argue that fuelled by cultural norms that dictate that a woman's place is in the home, there is sometimes a lack of understanding by family members about the demands of women's work outside the home that makes childcare assistance not so readily forthcoming.

In addition the SFWE recognises that:

“Many women who are socially excluded are deterred from using local business support both physically, for reasons of location and transport, and psychologically. This is 
particularly true of women who live in disadvantaged areas, are from BME groups or have disabilities". (p.14)

However, the SFWE's acknowledgement of the diversity of female entrepreneurs and particularly BME women and their experiences (which are sometimes different, in substance and/or degree and to that of white women) is not reflected in the substantive action priorities recommended by the SFWE. Instead the document recommends that:

Wherever appropriate, outreach activities and partnerships with relevant organisations should be used to reach this customer base. In many cases, a more effective approach will be to broker services to specialist agencies with expertise and experience working with the target groups. (p.14)

This additive approach may be grounded in the lack of research on BME female entrepreneurs, creating an information gap concerning their particular experiences and concerns. Ram (1997) highlights the under reported nature of the role of BME women in enterprise in spite of the significant contribution South Asian women make to family businesses (Barrett et al., 1996, Dhaliwal, 1997) and the fact that African Caribbean women are more likely to be selfemployed than their men. Also Struder's (2003) recent research among selfemployed Turkish-speaking women shows that for some immigrant women their perceived function in the community, for example as "mother and wife, guardian of gendered norms and practices" (p.190) impacts on the way they start and grow their businesses. Interestingly, in assessing the research gaps on female entrepreneurship, the SFWE fails to acknowledge this information gap on BME women entrepreneurs per se, albeit it does recognise their significant contribution to family-owned BME firms and highlights some of the issues that all "socially excluded" women may face in their bid to run their own businesses. Further, under the action implications in the SFWE for the SBS, there is a requirement for the SBS to establish "standardised recording and collection of gender-disaggregated data" without a similar requirement to collect such data by both gender and ethnicity. The assumption that gender discrimination takes precedence over all other factors in the current labour market experiences of all women is a presumptive one. For many BME women, gender, race and class have a different impact and influence in their working lives and they experience variable degrees of discrimination based on the interaction of gender, ethnicity, class and other arbitrary criteria in their lives.

One result of an approach that sees issues of ethnicity and the participation of BME women in entrepreneurship as an "outreach" issue rather than a substantive policy issue is that the concerns of BME women are marginalised. Hooks' (2000) definition of marginalisation is "to be part of the whole but outside the main body" and this definition indeed is a summation of the position of BME women in the policy approach towards female entrepreneurship. Further Crenshaw (1989) argues that any analysis of a group that progresses along a single trajectory (e.g. race or sex) tends to limit 
the enquiry to the dominant members of that group. In this sense BME women suffer a double disadvantage. Programmes that target 'BME businesses' benefit men who are the dominant members of that group and those that target 'women' benefit mainly White women. The inability to recognise the compound nature of discrimination that BME women face as well as their different belongings means that their concerns tend to be marginalised.

\section{Conclusions and recommendations}

The SFWE is an instrument that allows the inequities faced by female entrepreneurs to be highlighted and addressed at various levels. Its focus on specific action priorities allows policy initiatives in respect of business support to centre on particular aspects of female entrepreneurship that have for years been raised as barriers and challenges to increased female enterprise in the literature on the subject. Coupled with the proposed Women's Enterprise Centre that will monitor the status of female entrepreneurship in Britain and lobby government in favour of women business owners, the SFWE raises awareness of the importance of female enterprise and sets the agenda for improved business support for women's businesses. Of course there is a continuum of experiences with regard to the action priorities suggested by the SFWE. While some women establish enterprises without experiencing these barriers, it is important to take action to remove such barriers where they are encountered.

However, the SFWE's approach to the issue of BME women's entrepreneurship as a sub-set of female entrepreneurship and the assumption that they will benefit from all gender-based policy and initiatives dismisses situations where the needs women may differ from each other as a result of the interaction of different trajectories in their experiences and indeed where that of BME women may differ from those of White women. This paper's review of the experiences of BME women in self-employment and the labour market, in the light of action priorities identified by the SFWE that will help support those women who are already in business and encourage those who are desiring to do so, not only reveals particular needs and employment profiles, but also illustrates the multitude and complexity of barriers faced by some of them. New methodologies and approaches to policy making need to be developed in order to unearth the ways in which multiple identities converge to create and exacerbate women's subordination. These methodologies will underscore the importance of the intersection of 'race', ethnicity, gender, migration and disability for marginalised women and also emphasise the full diversity of women's experiences.

The Centre for Women's Global Leadership located in the United States, based on the United Nations definition of intersectionality quoted above have developed a methodological approach to intersectionality that addresses the issues raised by this paper. They recommend a four-stage approach that involves data collection, contextual analysis, intersectional review of policy initiatives and systems of implementation and finally, implementation of intersectional policy initiatives. The first is a requirement for the collection of data disaggregated by 'race', gender, ethnicity, migrant status, and other identities that will enable the evaluation of the real problems encountered by 
women who face these issues. Given the lack of widely available disaggregated data on women in entrepreneurship it would seem that this should be the starting point for policy makers in the UK The second stage involves a contextual analysis that locates the experiences of the women within particular situations to gain an understanding of how the various identities converge to create unique experiences of disadvantage. Thirdly a review of existing and proposed policy initiatives should be measured against the identified problems to evaluate how well they address the problems in the light of the intersectional experiences of groups of women and finally a well thought out intersectional policy initiative that addresses these concerns is implemented and reviewed. 


\section{References}

ANTHIAS, F. \& MEHTA, N. (2003) The Intersection Between Gender, the Family and Self-Employment: The Family as a Resource. International Review of Sociology, Vol. 13, No. 1, pp. 105-116.

ATHERTON, A. \& LYON, F. (2001) Segmenting Support for Small and Medium Enterprises, London, Report prepared for Small Business Service of the DTI.

BANK OF ENGLAND (2003) Finance for Small Firms: A Tenth Report, London, Report prepared for Bank of England.

BARRETT, G. A., JONES, T. P. \& MCEVOY, D. (1996) Ethnic Minority Business: Theoretical Discourse in Britain and North America. Urban Studies, Vol. 33 No. 4-5, pp. 783-809.

BERTHOUD, R. (1998) The Incomes of Ethnic Minorities, Colchester, Institute for Social and Economic Research.

BIRCH, D. (1979) The Job Generation Process, Massachusetts, Report prepared for Massachusetts Institute of Technology.

BRADSHAW, J., FINCH, N., KEMP, P. A., MAYHEW, E. \& WI LLIAMS, J. (2003) Gender and Poverty in Britain, No. 6, London, Report prepared for Equal Opportunities Commission.

BRUSH, C. (1990) Women and Enterprise Creation. IN Gould, S. \& Parzen, J. (Eds.) Women, Entrepreneurship and Economic Development. Paris, Organisation for Economic Cooperation and Development (OECD).

BRUSH, C. G. \& HISRICH, R. D. (1999) Women-Owned Businesses: Do They Matter? IN Acs, Z. J. (Ed.) Are Small Firms Important? Their Role and I mpact. Norwell, MA, Kluwer Academic Publishers.

CABINET OFFICE (2003) Ethnic Minorities and the Labour Market - Final Report, London, Report prepared for Strategy Unit, Cabinet Office.

CARTER, S., ANDERSON, S. \& SHAW, E. (2001) Women's Business Ownership: A Review of the Academic Popular and Internet Literature, RR002/01, Sheffield, Report prepared for Small Business Service.

CARTER, S., TAGG \& BRIERTON, J. (2002) Restricted Access: Women Owned Businesses in Profile, Prowess - FSB.

CRE (2005) Submission to the Women and Work Commission, Scotland, Report prepared for Women and Work Commission.

CRENSHAW, K. (1989) Demarginalizing the Intersection of Race and Sex: A Black Feminist Critique of Anti-discrimination Doctrine, Feminist Theory and Antiracist Policies. University of Chicago Legal Forum, Vol. 139.

CROMIE, S. \& HAYES, J. (1988) Towards a Typology of Female Entrepreneurs. Sociological Review, Vol. 36, No. 1, pp. 87-113.

DAWE, A. J. \& FIELDEN, S. L. (2005) The Experiences of Asian women Entering Business Start-Up in the UK. IN Fielden, S. L. \& Davidson, M. J. (Eds.) International handbook of Women and Samll Business Entrepreneurship. Cheltenham, Edward Elgar.

DEAKINS, D., WI LSON, L. \& WHITTAM, G. (2003) Developing Policy for Women's Enterprise: A Critical Examination of National Policies Paper presented to 26th ISBA National Small Firms Policy and Research Conference: SMEs in the Knowledge Economy, Egham, Surrey, 12-14th November 2003. 
DHALIWAL, S. (1997) Silent Contributors-Asian Female Entrepreneurs Paper presented to National Small Firms Policy and Research Conference, Belfast, Nov.

DHALIWAL, S. (2000) Asian Female Entrepreneurs and Women in Business an Exploratory Study. Enterprise and Innovation Management Studies, Vol. 1, No. 2, pp. 207-216.

DTI (2002a) Cross Cutting Review of Government Service for Small Business, URN 02/1324, Report prepared for Department of Trade and Industry.

DTI (2002b) Small Business and Government: The Way Forward, Department of Trade and Industry.

DTI (2003) A Strategic Framework for Women's Enterprise, London, Department of Trade and Industry.

FELSTEAD, A., JEWSON, N., PHIZACKLEA, A. \& WALTERS, S. (2000) A statistical portrait of working at home in the UK: Evidence from the labour force survey, Centre for Labour Market Studies, University of Leicester.

HALL, K., BANCE, J. \& DENTON, N. (2004) Diversity and difference: Minority ethnic mothers and childcare, London, Report prepared for Women and Equality Unit, Department of Trade and Industry.

HOOKS, B. (2000) Feminist Theory: From Margin to Center, Cambridge, MA, South End Press.

INMAN, K. (2000) Women's Resources in Business Start-Up: A Study of Black and White Women Entrepreneurs, New York, Garland Publishing.

MARLOW, S., WESTALL, A. \& WATSON, E. (2003) Who Benefits? The difficulties for women making the transition from unemployment to selfemployment, London, New Economics Foundation and Prowess.

MASON, S. (2003) Self-employment Policies from the Perspective of Citizenship, Gender and Ethnicity. International Review of Sociology, Vol. 13, No. 1, pp. 219-234.

OMAR, A., DAVIDSON, M. J., FIELDEN, S., HUNT, C. \& DAWE, A. J . (2004) A Pilot Study to Investigate the Problems, Experiences and Barriers faced by a Cross Section of Black and Ethnic Minority Female Entrepreneurs (SMEs) in the North West, Manchester, Centre for Diversity and Work Psychology, Manchester School of Management.

PHIZACKLEA, A. \& RAM, M. (1995) Ethnic Entrepreneurship in Comparative Perspective. International J ournal of Entrepreneurial Behaviour and Research, Vol. 1, No. 1, pp. 48-58.

PLATT, L. \& NOBEL, M. (1999) Race, Place and Poverty: Ethnic Groups and Low Income Distributions, YPS.

RAM, M. (1997) Ethnic Minority Enterprise: An Overview and Research Agenda. International J ournal of Entrepreneurial Behaviour \& Research, Vol. 3, No. 4, pp. 149-156.

RAM, M. (1998) Enterprise Support and Ethnic Minority Firms. J ournal of Ethnic and Migration Studies, Vol. 21, No. 1, pp. 143-158.

RAM, M. \& SMALLBONE, D. (2003) Policies to Support Ethnic Minority Enterprise: The English Experience. Entrepreneurship and Regional Development, Vol. 15, pp. 151-166. 
RAM, M., SMALLBONE, D. \& DEAKINS, D. (2003) Access to Finance by Ethnic Minority Businesses in the UK. International Small Business J ournal, Vol. 21, No. 3, pp. 291-314.

RANA, B. J., KAGAN, C., LEWIS, S. \& ROUT, U. (1998) British South Asian Women Managers and Professionals: Experiences of Work and Family Women in Management Review, Vol. 13, No. 6, pp. 221-232.

ROUSE, J. \& KITCHING, J. (2005) Do Enterprise Support Programmes Leave Women Holding the Baby? Environment and Planning C: Government and Policy, Vol. 24, No. 1 (February), pp. 5-19.

SBS (2001) Small and Medium-Sized Enterprise (SME) Statistics for the UK 2001, Small Business Service http://www.sbs.gov.uk/statistics (accessed 20/04/2005).

SBS (2004) Childcare and Enterprise: What available data tells us?, Small Business Service http://www.sbs.gov.uk/SBS_Gov_files/services/childcare.pdf (accessed 03/07/2005).

SCASE, R. (2000) The Enterprise Culture: The Socio-Economic Context of Small Firms. IN Carter, S. \& Jones-Evans, D. (Eds.) Enterprise and Small BusinessEnterprise and Small Business. Harlow, Financial Times-Prentice Hall.

SMALL BUSINESS SERVICE (2002) Income Bridge Evaluation and Research, London, Report prepared for Small Business Service.

STRUDER, I. (2003) Self-Employed Turkish-Speaking Women in London: Opportunities and Constraints. International J ournal of Entrepreneurship and Innovation, Vol. 4, No. 3, pp. 185-195.

VYAKARNAM, S. \& GATT, E. (2000) Small Business Service: Reinventing the wheel - will it make a difference? Paper presented to ISBA National Small Firms Policy and Research Conference, Aberdeen, November 2000.

WILSON, L., WHITTAM, G. \& DEAKINS, D. (2004) Women's Enterprise: A Critical Examination of National Policies. Environment and Planning C, Government and Policy, Vol. 22, pp. 799-815. 